Society for Epilepsy, Chalfont St Peter, Gerrards Cross Bucks SL9 ORJ, UK).

COMMENT. TV-induced seizures are likely to be less common in America than in Great Britain because of the differences in flicker rate patterns $(60 \mathrm{~Hz}$ vs $50 \mathrm{~Hz}$ ). Computers vary in flicker rate, and their tendency to induce seizures is independent of the main frequency. Sleep deprivation was a contributing factor in a significant number of patients in this study. The length of play sessions was not a hazard.

\title{
ICTUS EMETICUS AND NONDOMINANT TEMPORAL LOBE
}

Two patients, aged 18 and 47 years, with ictal vomiting during temporal lobe seizures documented with bilateral depth electrodes are reported from the Department of Neurology, New York School of Medicine, Hospital for Joint Diseases, New York. Vomiting developed when the seizure discharge spread to the right temporal lobe of one patient. In the other patient who was lefthanded and had right-hemisphere language dominance, ictal vomiting was associated with a left temporal discharge. These cases supported the localization of ictal vomiting in the nondominant temporal lobe. (Devinsky $\mathrm{O}$ et al. Ictus emeticus: Further evidence of nondominant temporal involvement. Neurology June 1995;45:1158-1160). (Reprints: Dr Orrin Devinsky, Department of Neurology, Hospital for Joint Disease, 301 East 17 th St, New York, NY 10003).

COMMENT. The authors cite 16 previous reports of ictal vomiting, the first dated 1982, with right temporal foci in 14. In a 1955 report from the Children's Medical Center, Boston, 33 children with cyclic vomiting, 7 (21\%) having a history of complex partial or generalized seizures and 25 (76\%) with seizure discharges in the EEG, some focal with temporal localization, were thought to have a form of epilepsy. (Millichap JG, Lombroso CT, Lennox WG. Pediatrics 1955;15:705). Ictal vomiting is discussed in Progress in Pediatric Neurology I, Chicago, PNB Publ, 1991, pp46-47.

\section{SERUM PROLACTIN AND NEONATAL SEIZURES}

Serum prolactin (PRL) levels were studied in 28 newborn infants with acute encephalopathy (6 with seizures and 22 without) at the Children's Hospital of Philadelphia and St Christopher's Hospital for Children, Philadelphia, PA. Serum PRL was significantly higher at baseline and $15 \mathrm{~min}$ postictally in patients with seizures than in the nonictal group, but postictal levels were not different from baseline values. In both groups, patients with abnormal EEG backgrounds had higher PRL levels than those with normal EEG background. (Legido A et al. Serum prolactin in neonates with seizures. Epilepsia July 1995;36:682-686). (Reprints: Dr A Legido, Section of Neurology, St Christopher's Hospital for Children, Erie Ave at Front St, Philadelphia, PA 19134).

COMMENT. Newborns with EEG confirmed seizures, but without clinical manifestations, have high base-line serum PRL levels that do not increase postictally. These findings were contrary to those recently reported by Morales et al (1995) who found that only newborns with electroclinical seizures, not those with subclinical EEG seizures, had a significant postictal increase in PRL. Serum PRL levels correlate with the severity of the acute neonatal encephalopathy, as determined by the EEG background changes. 